\title{
Maximum Entropy Ecological Niche Prediction of the Current Potential Geographical Distribution of Eimeria Species of Cattle, Sheep and Goats in Mexico
}

\author{
Yazmin Alcala-Canto ${ }^{*}$, Aldo Alberti-Navarro², Juan Antonio Figueroa-Castillo', \\ Froylan Ibarra-Velarde1, Yolanda Vera-Montenegro', Maria Eugenia Cervantes-Valencia ${ }^{3}$ \\ ${ }^{1}$ Facultad de Medicina Veterinaria y Zootecnia, Departamento de Parasitología, UNAM, Mexico City, Mexico \\ ${ }^{2}$ Facultad de Medicina Veterinaria y Zootecnia, Departamento de Medicina y Zootecnia de Rumiantes, UNAM, Mexico City, Mexico \\ ${ }^{3}$ Facultad de Medicina, Departamento de Biologia Celular y Tisular, UNAM, Mexico City, Mexico \\ Email: *yazmin@unam.mx
}

How to cite this paper: Alcala-Canto, Y., Alberti-Navarro, A., Figueroa-Castillo, J.A., Ibarra-Velarde, F., Vera-Montenegro, Y. and Cervantes-Valencia, M.E. (2019) Maximum Entropy Ecological Niche Prediction of the Current Potential Geographical Distribution of Eimeria Species of Cattle, Sheep and Goats in Mexico. Open Journal of Animal Sciences, 9, 234-248. https://doi.org/10.4236/ojas.2019.92020

Received: March 7, 2019

Accepted: April 14, 2019

Published: April 17, 2019

Copyright $\odot 2019$ by author(s) and Scientific Research Publishing Inc. This work is licensed under the Creative Commons Attribution International License (CC BY 4.0).

http://creativecommons.org/licenses/by/4.0/ (c) (i) Open Access

\begin{abstract}
Coccidiosis is a gastrointestinal disease caused by parasites of the genus $E i$ meria. To produce the ecological niche model for the geographic distribution of Eimeria species, the maximum entropy algorithm (MaxEnt) was used and 19 bioclimatic variables with a spatial resolution of 30 arc-seconds (approximately $1 \mathrm{~km}^{2}$ ) were downloaded from the World Climate Database. These were reduced to $\mathrm{BIO} 2, \mathrm{BIO} 3, \mathrm{BIO} 4, \mathrm{BIO} 7$ and $\mathrm{BIO} 15$ for each species after examining cross-correlations among them to account multicollinearity. A jackknife analysis was included to assess the contribution of five bioclimatic variables and the fit of the model was evaluated with the area under receiver operating characteristic curve (AUC). Under a current climate scenario, the jackknife evaluation of the MaxEnt model showed that BIO4 (temperature seasonality) made the greatest contribution to the distribution model for 22 Eimeria species; whereas BIO7 (temperature annual range) was the most important factor that contributes to the distribution model of 10 species. The habitat suitability model based on the maximum entropy theory was supported by AUC values higher than 0.9 and predicted that the suitable habitats for different species of Eimeria are present in southern, eastern and western areas of Mexico. Our study may support future studies exploring factors that constrain the distribution of Eimeria as well as strategies aimed at reducing the disease prevalence.
\end{abstract}

\section{Keywords}

Eimeria, MaxEnt, Ruminants, Coccidiosis, Habitat Suitability 


\section{Introduction}

Coccidiosis is a gastrointestinal disease caused by parasites of the genus Eimeria. Environmental and climatic factors are relevant for development, survival and transmission of coccidiosis in large and small ruminants. Temperature, rainfall, solar radiation, soil type and $\mathrm{pH}$, altitude or elevation and vegetation index influence the spatial distribution of parasites [1]. Climate is considered to strongly affect the emergence, spread and frequency of infectious disease outbreaks and tolerance to different climate conditions may lead to divergent geographical distributions [2]. For instance, Eimeria infectious oocysts are able to survive in the environment for several weeks or months in favorable conditions of moderate heat and moisture [3]. A growing body of evidence emphasizes the importance of incorporating data derived from geographic information systems and predictive niche models to support epidemiological studies and develop accurate distribution forecasts [2]. Geographic information systems have been currently used to create spatial distribution maps and ecological niche modeling has been used to evaluate the ecological requirements, responses and distribution areas of several species of parasites such as Lutzomyia [4], cattle fever ticks [5], avian blood parasites [6], Fasciola hepatica [7] [8], Angiostrongylus cantonensis [9], Opisthorchis viverrini [8] [10], among others. Rhipicephalus (Boophilus) spp. locations have been recently georeferenced and the spatial distribution of the tick in Mexico was modeled [11] [12] [13]. Consequently, the knowledge of the bioecology of parasites, such as their habitat suitability, might support studies that increase preventive or control measures to avoid their further distribution.

Despite significant advances in studies of the epidemiology of coccidiosis in Mexico, there is scarce organized information and a lack of ecological niche models that consider abiotic interactions when predicting current parasite distributions, thus the precise spatial distribution of the parasite in this country is still unknown. Within this context, the aim of the present study was to model the potential current spatial distribution of the parasite using data on a range of bioclimatic parameters.

\section{Material and Methods}

\section{Study Area}

Mexico is located in the region of North America and bordered by the United States of America in the north, Guatemala and Belize in the south, the Atlantic and Pacific Oceans in the east and west, respectively. Altitude is one factor the affects the climate of Mexico. Thus, five main climates exist, which can be generally classified according to temperature in warm and temperate; and according to precipitation in: humid, subhumid and very dry [14]. The latter is present mostly in $20.8 \%$ of the country, mainly in the northern regions. These locations have mean annual temperatures of $18^{\circ} \mathrm{C}-26^{\circ} \mathrm{C}$ and a mean annual precipitation of 100 to $300 \mathrm{~mm}$. Warm humid climate is present in the southern region and represents $4.7 \%$ of Mexico. Mean annual temperature is $22^{\circ} \mathrm{C}$ to $26^{\circ} \mathrm{C}$ and preci- 
pitation ranges from 2000 to $4000 \mathrm{~mm}$ per year. Warm subhumid climate is present in $23 \%$ of the country with a mean annual temperature that sometimes overcome $26^{\circ} \mathrm{C}$ with 1000 to $2000 \mathrm{~mm}$ of annual rainfall. Finally, humid temperate climate is present in the mountainous ridges and represent $2.7 \%$ of the territory. Annual mean temperature ranges from $18^{\circ} \mathrm{C}$ to $22^{\circ} \mathrm{C}$ and annual precipitation ranges from 2000 to $4000 \mathrm{~mm}$ [15]. Hence, the seasonal distribution of precipitation is uneven and may influence the richness in wildlife species and ecosystem types.

\section{Data Collection}

A systematic literature review was performed to record occurrences of Eimeria into a database in Microsoft Excel 2016. Documents such as articles, thesis, diagnosis records, abstracts and conference proceedings reporting natural infections of this parasite were integrated. Data of Eimeria were included into a database with information about the year, location, state and reference or case number of the occurrence of the parasite. Latitude and longitude for each record were determined using Google Earth. Data were analyzed to avoid redundancy of occurrences [16] [17].

\subsection{Environmental Data}

To produce the ecological niche model for the geographic distribution of Eimeria species that infect cattle, sheep and goats in Mexico, 19 bioclimatic variables with a spatial resolution of 30 arc-seconds (approximately $1 \mathrm{~km}^{2}$ ) were downloaded from the World Climate Database (BIO1 = Annual Mean Temperature; $\mathrm{BIO} 2$ = Mean Diurnal Range (Mean of monthly (max temp - min temp)); BIO3 $=$ Isothermality $(\mathrm{BIO} 2 / \mathrm{BIO} 7)\left({ }^{\star} 100\right) ; \mathrm{BIO} 4=$ Temperature Seasonality (standard deviation $\left.{ }^{\star} 100\right)$; BIO5 $=$ Max Temperature of Warmest Month; BIO6 = Min Temperature of Coldest Month; BIO7 = Temperature Annual Range (BIO5 BIO6); BIO8 = Mean Temperature of Wettest Quarter; BIO9 = Mean Temperature of Driest Quarter; BIO10 = Mean Temperature of Warmest Quarter; BIO11 $=$ Mean Temperature of Coldest Quarter; BIO12 = Annual Precipitation; BIO13 = Precipitation of Wettest Month; BIO14 = Precipitation of Driest Month; BIO15 = Precipitation Seasonality (Coefficient of Variation); BIO16 = Precipitation of Wettest Quarter; BIO17 = Precipitation of Driest Quarter; BIO18 = Precipitation of Warmest Quarter; BIO19 = Precipitation of Coldest Quarter) [18].

\subsection{Ecological Niche Model}

The maximum entropy algorithm (MaxEnt version 3.3.3.k) [19] was used for model construction and to produce prediction maps of environmental suitability. For each Eimeria species, $75 \%$ of the occurrence data were used as a training model, and the remaining $25 \%$ was used for model validation [20]. This study set the default parameters of MaxEnt. A logistic output format was chosen to assign values for each grid cell ranging from unsuitable (0) to fully suitable (1). 


\subsection{Statistical Analysis}

Ten MaxEnt runs were performed for each species to evaluate the predictive power of the algorithm, each with the same number of occurrence points [21]. A jackknife analysis was used to assess the contribution of bioclimatic variables in MaxEnt. The jackknife was proposed by M.H. Quenouille in 1945 and given its name by John Tukey 11 years later. The procedure was developed to correct bias and to construct confidence limits for a large class of estimators by involving resampling without replacement [22] [23] [24]. The bioclimatic variable with highest gain for each Eimeria species is the one that, according to the jackknife analysis, has the most useful information by itself. The environmental variable that decreases the gain the most when it is omitted is the one that appears to have the most information that is not present in the other variables [25] [26]. In contrast, variables with no contribution in the test were excluded from the final analysis.

\section{Results}

\section{Habitat Suitability Modelling}

The 19 bioclimatic variables were reduced to $\mathrm{BIO} 2, \mathrm{BIO} 3, \mathrm{BIO} 4, \mathrm{BIO} 7$ and BIO15 for each species after examining cross-correlations among them to account multicollinearity [27]. The AUC for training and testing data was calculated for each Eimeria species. The climatic suitability for Eimeria species distribution in Mexico predicted by the best performing MaxEnt model are shown in maps in which warmer colours depict areas with higher climatic suitability for Eimeria species that infect cattle (Figure 1), sheep (Figure 2) and goats (Figure 3).

Eimeria species were predicted to be present in most central and southern parts of Mexico, even though there are regions of high habitat suitability in the western area, as well. The MaxEnt algorithm assessed the relevance of the variables that contribute to Eimeria spatial distribution through jackknife analysis of the contribution of each climatic variable to the model, the average values of AUC of 10 model iterations and the average percentage contribution of each variable to the model.

To determine the relative contribution of the bioclimatic variables in the spatial distribution of Eimeria species of cattle (Table 1), sheep (Table 2) and goats (Table 3), the values for each bioclimatic variable on training presence and background data are randomly permuted [26].

A jackknife technique was used for variance estimation as it derives estimates of the bioclimatic variable of interest from each of several subsamples of the parent sample and then estimates the variance of the parent sample estimator from the variability between the subsample estimates [28].

Under a current climate scenario, the jackknife evaluation of the MaxEnt model demonstrated that BIO4 (temperature seasonality) made the greatest contribution to the distribution model for E. alabamensis, E. bovis, E. brasiliensis, 
Table 1. Permutation importance (\%) of bioclimatic variables to the spatial distribution of Eimeria spp. of cattle.

\begin{tabular}{|c|c|c|c|c|c|c|c|c|c|c|c|c|c|}
\hline & 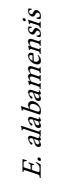 & 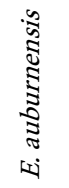 & $\begin{array}{l}3 \\
\vdots \\
\vdots \\
\vdots\end{array}$ & 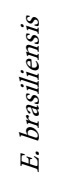 & 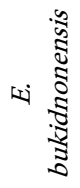 & 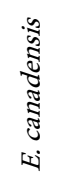 & 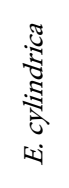 & 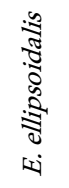 & 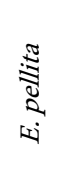 & 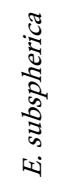 & 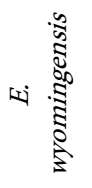 & 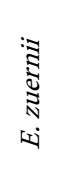 & 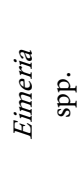 \\
\hline $\mathrm{BIO} 2$ & 2.1 & 1.4 & 0.9 & 0 & 0.1 & 0 & 0 & 0 & 0 & 2.9 & 0 & 0.1 & 0.3 \\
\hline BIO3 & 1.7 & 4.7 & 10.1 & 1.3 & 0.5 & 1.4 & 10.5 & 0 & 3.5 & 0.6 & 0.7 & 11.9 & 2.4 \\
\hline BIO4 & 52.2 & 23.5 & 66.3 & 54.9 & 71.7 & 50.9 & 42.6 & 62 & 30.6 & 50 & 76.9 & 35.3 & 81.8 \\
\hline BIO7 & 43.5 & 63.6 & 17.1 & 43.1 & 26 & 47.6 & 45.3 & 37.5 & 65 & 46.1 & 22.4 & 49.2 & 14 \\
\hline BIO15 & 0.5 & 6.7 & 5.6 & 0.7 & 1.7 & 0.2 & 1.6 & 0.6 & 0.8 & 0.3 & 0 & 3.5 & 1.5 \\
\hline
\end{tabular}

$\mathrm{BIO} 2=$ Mean Diurnal Range (Mean of monthly (max temp - min temp)); BIO3 = Isothermality (BIO2/BIO7) $\left({ }^{*} 100\right)$; BIO4 = Temperature Seasonality (standard deviation $\left.{ }^{\star} 100\right) ; \mathrm{BIO} 7=$ Temperature Annual Range $\left(\mathrm{BIO}\right.$-BIO6); BIO15 = Precipitation Seasonality (Coefficient of Variation). ${ }^{*}$ The MaxEnt model was reevaluated on the permuted data of training presence and background data for each bioclimatic variable, and the resulting drop in training AUC is shown normalized to percentages.

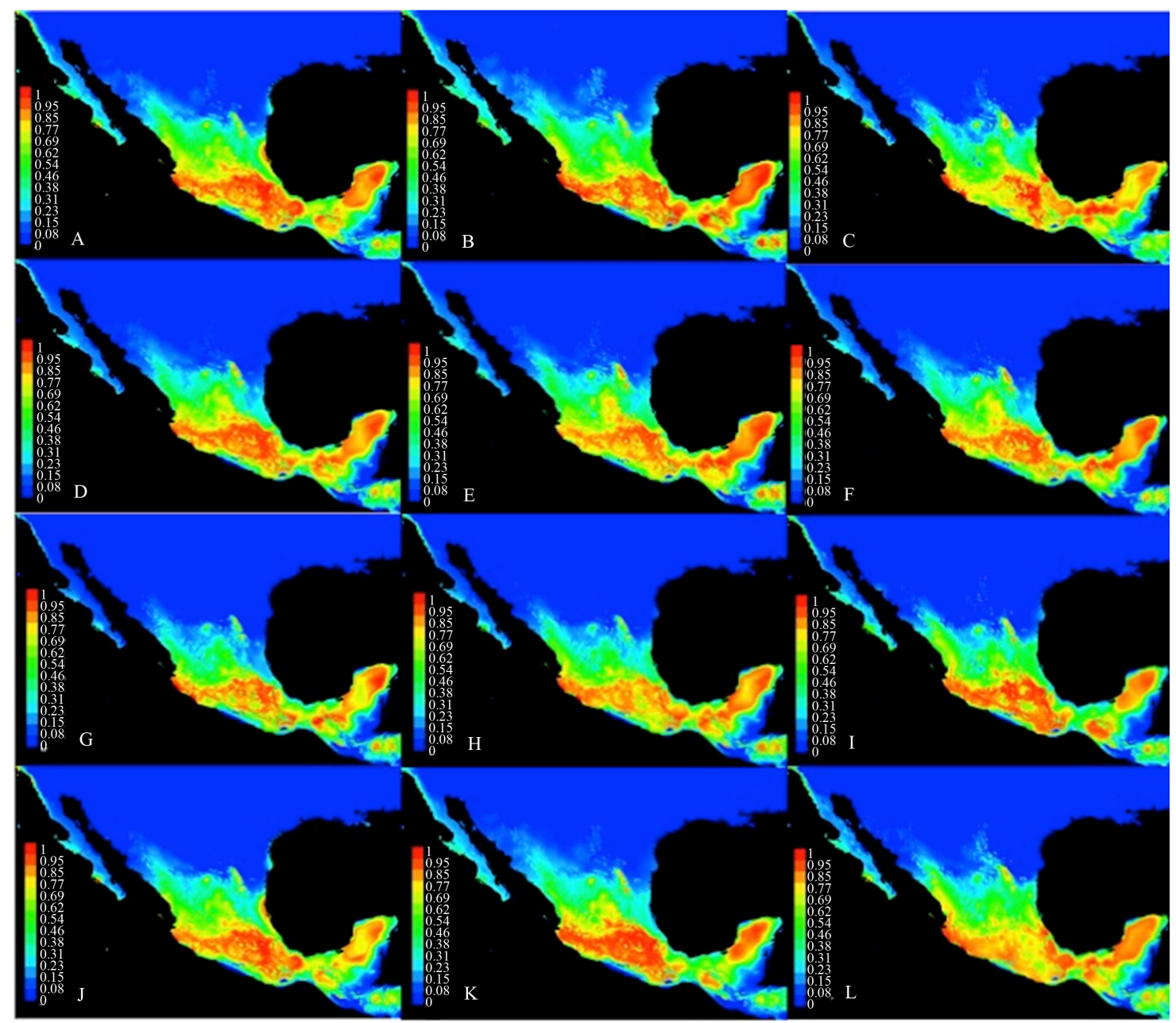

Figure 1. Habitat suitability maps developed with a Maximum Entropy prediction algorithm for Eimeria species that infect cattle. (A) E. alabamensis, (B) Eimeria auburnensis, (C) E. bovis, (D) E. brasiliensis, (E) E. bukidnonensis, (F) E. canadensis; (G) E. cylindrica; (H) E. ellipsoidalis; (I) E. pellita; (J) E. subspherica; (K) E. wyomingensis; (L) E. zuernii. A logistic output format was chosen to assign values for each grid cell ranging from unsuitable (0) to fully suitable (1). Warmer colours depict areas with higher climatic suitability for Eimeria species. 
Table 2. Permutation importance* (\%) of bioclimatic variables to the spatial distribution of Eimeria spp. of sheep.

\begin{tabular}{|c|c|c|c|c|c|c|c|c|c|c|c|}
\hline & E. ahsata & E. bakuensis & E. crandallis & E. faurei & i E. granulosa & E. intrincata & E. ovinoidalis & S E. pallida & E. parva E. & weybridgensis & Eimeria spp. \\
\hline $\mathrm{BIO} 2$ & 0.2 & 0.1 & 0.7 & 0 & 1.6 & 0 & 3.3 & 0 & 3.4 & 0 & 0 \\
\hline $\mathrm{BIO} 3$ & 0 & 1.7 & 1.9 & 2.1 & 0 & 0 & 0 & 1.8 & 5.2 & 1.7 & 5.9 \\
\hline BIO4 & 78.3 & 73.2 & 43.3 & 70 & 56.2 & 59.3 & 22.9 & 71.8 & 34.2 & 60.4 & 39.6 \\
\hline BIO7 & 21.2 & 24.4 & 52 & 27.2 & 40.7 & 40.7 & 73.7 & 24.9 & 57.1 & 37.8 & 51.2 \\
\hline BIO15 & 0.4 & 0.5 & 2.1 & 0.7 & 1.6 & 0 & 0.2 & 1.6 & 0 & 0.2 & 3.3 \\
\hline
\end{tabular}

BIO2 = Mean Diurnal Range (Mean of monthly (max temp - min temp)); BIO3 = Isothermality (BIO2/BIO7) $\left({ }^{\star} 100\right)$; BIO4 = Temperature Seasonality (standard deviation $\left.{ }^{\star} 100\right) ; \mathrm{BIO} 7=$ Temperature Annual Range $\left(\right.$ BIO5-BIO6); BIO15 = Precipitation Seasonality (Coefficient of Variation). ${ }^{*}$ The MaxEnt model was reevaluated on the permuted data of training presence and background data for each bioclimatic variable, and the resulting drop in training AUC is shown normalized to percentages.

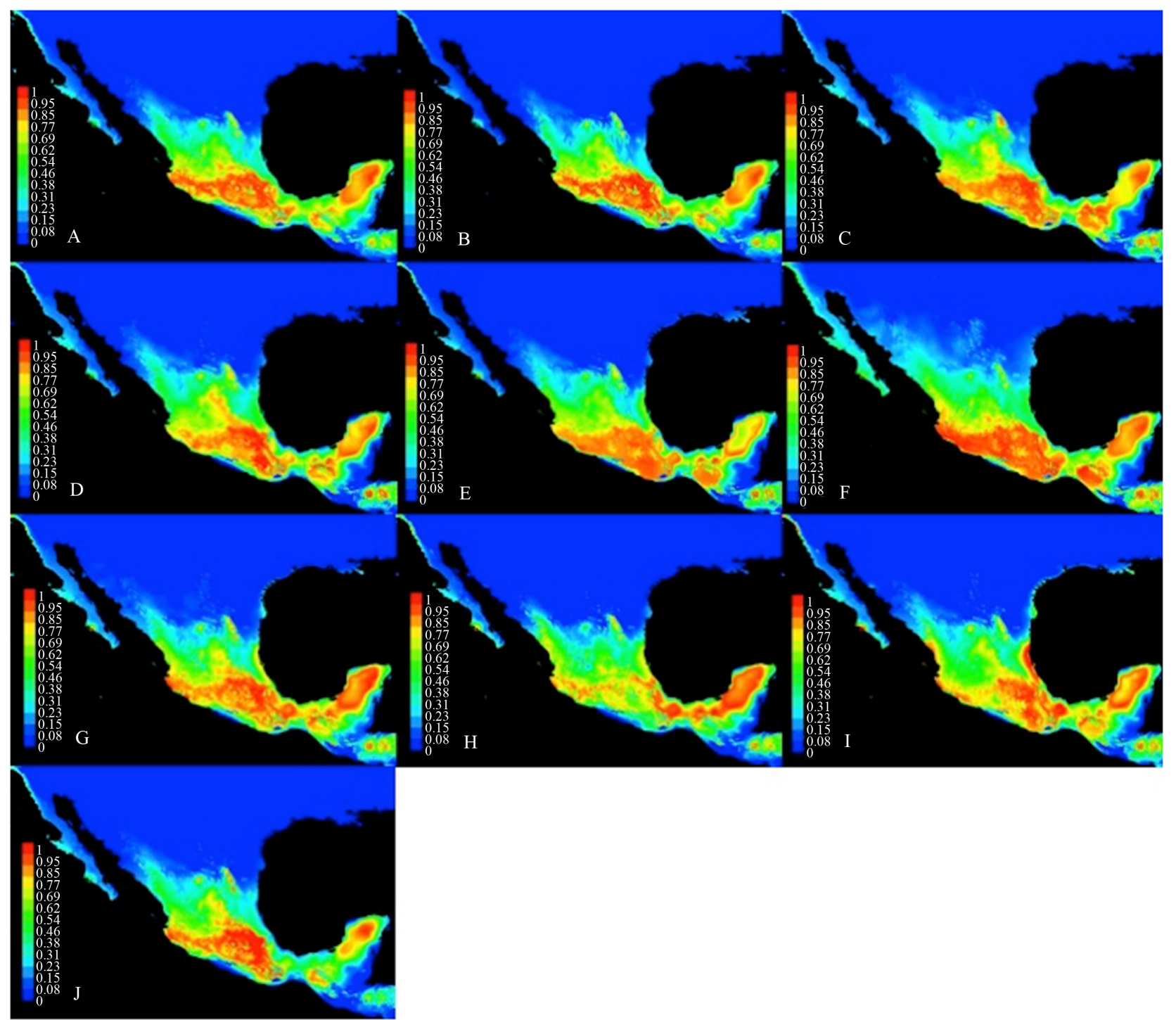

Figure 2. Habitat suitability maps developed with a Maximum Entropy prediction algorithm for Eimeria species that infect sheep. (A) E. ahsata; (B) E. bakuensis; (C) E. crandallis; (D) E. faurei; (E) E. granulosa; (F) E. intrincata; (G) E. ovinoidalis; (H) E. pallida; (I) E. parva; (J) E. weybridgensis. A logistic output format was chosen to assign values for each grid cell ranging from unsuitable (0) to fully suitable (1). Warmer colours depict areas with higher climatic suitability for Eimeria species. 
Table 3. Permutation importance* (\%) of bioclimatic variables to the spatial distribution of Eimeria spp. of goats.

\begin{tabular}{cccccccccc}
\hline & E. alijevi & Earloingi & E. caprina & E.caprovina & E. christenseni & E. hirci & E. jolchijevi & E. ninakohlyakimovae & Eimeria spp. \\
\hline BIO2 & 0 & 2 & 0 & 0 & 0 & 0.3 & 0 & 0.5 & 8.9 \\
BIO3 & 12.3 & 3.9 & 17.7 & 4.6 & 1.5 & 2.5 & 13.9 & 0 & 0 \\
BIO4 & 56.3 & 84.9 & 47.4 & 32.2 & 85 & 62.5 & 37.4 & 73.1 & 84.1 \\
BIO7 & 5.1 & 6.8 & 29.2 & 4.6 & 6.3 & 10 & 33.6 & 25.8 & 6.3 \\
BIO15 & 26.3 & 2.4 & 5.7 & 58.5 & 7.1 & 24.8 & 15.1 & 0.5 & 0.6 \\
\hline
\end{tabular}

$\mathrm{BIO} 2=$ Mean Diurnal Range $\left(\right.$ Mean of monthly (max temp - min temp)); BIO3 = Isothermality (BIO2/BIO7) $\left({ }^{\star} 100\right)$; BIO4 = Temperature Seasonality (standard deviation $\left.{ }^{\star} 100\right) ; \mathrm{BIO} 7=$ Temperature Annual Range $\left(\mathrm{BIO}\right.$-BIO6); BIO15 = Precipitation Seasonality (Coefficient of Variation). ${ }^{*}$ The MaxEnt model was reevaluated on the permuted data of training presence and background data for each bioclimatic variable, and the resulting drop in training AUC is shown normalized to percentages.

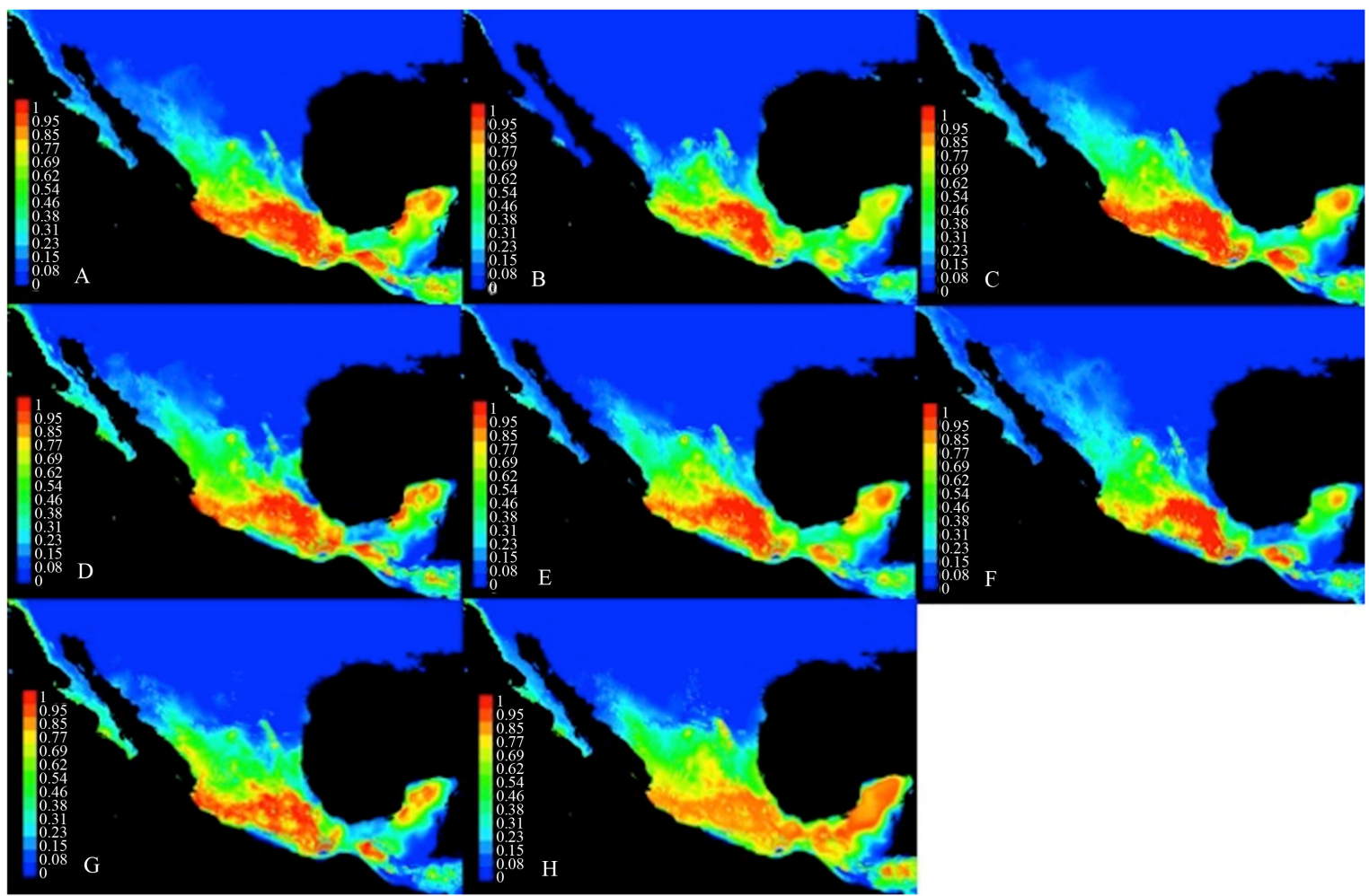

Figure 3. Habitat suitability maps developed with a Maximum Entropy prediction algorithm for Eimeria species that infect goats. (A) E. alijevi; (B) E. arloingi; (C) E. caprina; (D) E. caprovina; (E) E. christenseni; (F) E. hirci; (G) E. jolchijevi; (H) E. ninakohlyakimovae. A logistic output format was chosen to assign values for each grid cell ranging from unsuitable (0) to fully suitable (1). Warmer colours depict areas with higher climatic suitability for Eimeria species.

E. bukidnonensis, E. canadensis, E. cylindrica, E. ellipsoidalis, E. pellita, E. subspherical, E. wyomingensis, E. ahsata, E. bakuensis, E. faurei, E. ovinoidalis, E. pallida, E. alijevi, E. arloingi, E. caprina, E. caprovina, E. christenseni, E. hirci and E. ninakohlyakimovae. The MaxEnt model's internal jackknife test showed that BIO7 (temperature annual range) is the most important factor that contributes to the distribution model of E. auburnensis, E. pellita, E. zuernii, E. crandallis, E. faurei, E. garnulosa, E. intrincata, E. parva, E. weybridgensis and E. jolchijevi, relative to other variables (Table 4). 
Table 4. Main bioclimatic driver of Eimeria geographical distribution in Mexico.

\begin{tabular}{|c|c|}
\hline Eimeria species & Main driver of Eimeria distribution \\
\hline \multicolumn{2}{|l|}{ CATTLE } \\
\hline Eimeria alabamensis & Temperature Seasonality \\
\hline Eimeria auburnensis & Temperature Annual Range \\
\hline Eimeria bovis & Temperature Seasonality \\
\hline Eimeria brasiliensis & Temperature Seasonality \\
\hline Eimeria bukidnonensis & Temperature Seasonality \\
\hline Eimeria canadensis & Temperature Seasonality \\
\hline Eimeria cylindrica & Temperature Seasonality \\
\hline Eimeria ellipsoidalis & Temperature Seasonality \\
\hline Eimeria pellita & Temperature Annual Range \\
\hline Eimeria subspherica & Temperature Seasonality \\
\hline Eimeria wyomingensis & Temperature Seasonality \\
\hline Eimeria zuernii & Temperature Annual Range \\
\hline \multicolumn{2}{|l|}{ SHEEP } \\
\hline Eimeria ahsata & Temperature Seasonality \\
\hline Eimeria bakuensis & Temperature Seasonality \\
\hline Eimeria crandallis & Temperature Annual Range \\
\hline Eimeria faurei & Temperature Annual Range \\
\hline Eimeria granulosa & Temperature Annual Range \\
\hline Eimeria intrincata & Temperature Annual Range \\
\hline Eimeria ovina & Temperature Seasonality \\
\hline Eimeria ovinoidalis & Temperature Seasonality \\
\hline Eimeria pallida & Temperature Annual Range \\
\hline Eimeria parva & Temperature Annual Range \\
\hline \multicolumn{2}{|l|}{ Eimeria weybridgensis } \\
\hline \multicolumn{2}{|l|}{ GOAT } \\
\hline Eimeria alijevi & Temperature Seasonality \\
\hline Eimeria arloingi & Temperature Seasonality \\
\hline Eimeria caprina & Temperature Seasonality \\
\hline Eimeria caprovina & Temperature Seasonality \\
\hline Eimeria christenseni & Temperature Seasonality \\
\hline Eimeria hirci & Temperature Seasonality \\
\hline Eimeria jolchijevi & Temperature Annual Range \\
\hline Eimeria ninakohlyakimovae & Temperature Seasonality \\
\hline
\end{tabular}

As the model output shows, the bioclimatic suitability for all Eimeria species was predicted to be highest in humid and subhumid tropical and temperate climates. Furthermore, temperature seasonality (BIO4) and annual temperature range (BIO7) may be the main factors for the distribution of this parasite. The 
MaxEnt model accomplished an excellent fit with average test AUC values of over 0.9 for all the species (Table 5).

Table 5. Area under the ROC (receiver operating characteristic) curve or AUC metric used to evaluate the model performance of the Eimeria geographical distribution in Mexico.

\begin{tabular}{|c|c|}
\hline Eimeria species & Area Under the Curve value \\
\hline \multicolumn{2}{|l|}{ CATTLE } \\
\hline Eimeria alabamensis & 0.959 \\
\hline Eimeria auburnensis & 0.960 \\
\hline Eimeria bovis & 0.953 \\
\hline Eimeria brasiliensis & 0.960 \\
\hline Eimeria bukidnonensis & 0.962 \\
\hline Eimeria canadensis & 0.956 \\
\hline Eimeria cylindrica & 0.956 \\
\hline Eimeria ellipsoidalis & 0.969 \\
\hline Eimeria pellita & 0.969 \\
\hline Eimeria subspherica & 0.950 \\
\hline Eimeria wyomingensis & 0.960 \\
\hline Eimeria zuernii & 0.951 \\
\hline \multicolumn{2}{|l|}{ SHEEP } \\
\hline Eimeria ahsata & 0.973 \\
\hline Eimeria bakuensis & 0.963 \\
\hline Eimeria crandallis & 0.965 \\
\hline Eimeria faurei & 0.962 \\
\hline Eimeria granulosa & 0.968 \\
\hline Eimeria intrincata & 0.963 \\
\hline Eimeria ovina & 0.962 \\
\hline Eimeria ovinoidalis & 0.967 \\
\hline Eimeria pallida & 0.966 \\
\hline Eimeria parva & 0.974 \\
\hline \multicolumn{2}{|l|}{ Eimeria weybridgensis } \\
\hline \multicolumn{2}{|l|}{ GOAT } \\
\hline Eimeria alijevi & 0.965 \\
\hline Eimeria arloingi & 0.972 \\
\hline Eimeria caprina & 0.970 \\
\hline Eimeria caprovina & 0.962 \\
\hline Eimeria christenseni & 0.959 \\
\hline Eimeria hirci & 0.964 \\
\hline Eimeria jolchijevi & 0.965 \\
\hline Eimeria ninakohlyakimovae & 0.964 \\
\hline
\end{tabular}


It is safe to state that both bioclimatic variables are high for Mexican northwestern states that are located near monsoonal flows, which increase the variability of the synoptic atmospheric circulation. Thus, these regions have higher ranges of temperature variability [29]. Likewise, given the prediction model, one may conclude that even though Eimeria populations tolerate a wide range of temperatures, they are not able to sporulate in northwestern and central dry areas that have temperatures above $37^{\circ} \mathrm{C}$ or below $13^{\circ} \mathrm{C}$.

\section{Discussion}

It is well understood that Eimeria species are able to survive for prolonged periods of time in conditions of moderate heat and humidity [3] [30], yet oocysts are strongly affected by high temperatures and desiccation [31]. As the MaxEnt model output showed, if the climate conditions are warm, Eimeria presences increase, such as in the southern and central regions of Mexico. However, if the climate conditions are too hot, the survival rate of this parasite decreases, and colonization of areas is reduced. According to our results, Eimeria is scarcely present in the western and central areas of the northern region of Mexico. The low occurrences of Eimeria in Mexico may be attributed to climatic conditions required for their development, which was demonstrated by using the MaxEnt niche modelling approach. The predicted distribution of this parasite is limited in areas that have at least one month with mean temperatures higher than $30^{\circ} \mathrm{C}$, usually recorded in several areas above the Northern tropic (Tropic of Cancer). When temperature is too warm, oocysts are unable to sporulate [3], therefore reducing the infected population of hosts. The habitat suitability model based on the maximum entropy theory, predicted the potential habitat quality of different species of Eimeria in cattle, sheep and goats with an excellent fit of the algorithm $($ AUC $>0.90)$. The modelled habitat suitability using bioclimatic parameters proposed a distribution with temperature seasonality (BIO4) and temperature annual range (BIO7) constituting decisive factors. The parasite's habitat was mainly influenced by temperature seasonality (BIO4) for nine out of 12 species of cattle, four out of 10 species of sheep and seven out of eight species of goats. Interestingly, the annual temperature range (BIO7) variable was identified as the most critical factor shaping the distribution of the pathogenic E. zuernii. Similarly, the results of the jackknife test of variable importance showed that the bioclimatic variable with highest gain in the predicting power of the model when used in isolation was BIO7 for most Eimeria species that infect sheep in Mexico (E. crandallis, E. faurei, E. granulosa, E.intrincata, E. parva and E. weybridgensis), except for the highly pathogenic E. ovinoidalis. The highest contributions for Eimeria distribution arise for the warm-climate adapted species, suggesting the large influence of temperature on the colonization and survival of this parasite. These findings are not in conformity with other studies that conclude that rainfall and soil moisture is the most relevant factor that contributes to the prevalence of Eimeria [32] [33]. Similarly, authors have estimated $62 \%$ of positive 
calves in a dry region of Mexico [34], hence supporting the importance of precipitation as a pertinent factor driving the distribution of this parasite in Mexico. Previous results have indicated a correlation between temperature and humidity with seasonal factors, which indicated lower oocyst shedding during winter period compared to the fall [35]. Results reported by the authors of the latter study supported the theory than increased risk of faster sporulation of oocysts is due to internal environmental factors that consequently increase oocyst excretion. The jackknife test showed that $\mathrm{BIO} 4$ and $\mathrm{BIO} 7$ have the most useful information independent of the others, yet the heuristic test estimateda permutation importance higher than $20 \%$ for precipitation seasonality (BIO15) for three species of goats (E. alijevi, E. caprovina, E. hirci). It is reasonable to speculate that $\mathrm{BIO} 15$ ranked higher in the heuristic test than in the jackknife method because the model assigned a correlated effect with another variable to that particular one. The variance and bias estimation performed by the jackknife method when BIO15 was left out from the dataset, demonstrated that neither does this bioclimatic variable appear to have the most information by itself, nor does it appear to have the most information that is not present in the other variables [25] [26].

It would be a mistake to see the current study as definitive, as one major limitation was that our findings did not include information to support or reject macroecological patterns related to parasite distribution. It is well understood that spatial distribution of parasites is influenced by abiotic and biotic environments, such as temperature, precipitation, altitude, presence of predators, human disturbance, geographic barriers, soil type and vegetation among other factors [36] [37]. In fact, previous studies suggest that biotic factors will be more relevant at a species equatorial range limit; whereas abiotic factors will influence the high latitude or poleward limit [21].

Even though the high accordance between the distribution of Eimeria occurrence data and modelling results was supported by AUC values higher than 0.9, it would be unsafe to state that this species may colonize all predicted areas despite suitable climate, as both the model fit and prediction accuracy can be limited. Occurrence data can be affected by a sampling bias, as species were more commonly reported in some states due to the proximity of these regions to research institutions, resulting in unequal probabilities of records.

Climate in Mexico is influenced mostly by its geographic position. The modelling in the present study predicted suitable climatic conditions for this parasite in $50.9 \%$ of the country. Although some aspects of our dataset are limited, we are convinced that the encouraging results herein obtained would hopefully motivate researchers to use the predicted habitat suitability in areas and countries where similar climatic conditions as the ones reported here prevail. This information might support the implementation of preventive strategies and measures designed to control this parasite. Further studies that include abiotic and biotic factors in an integrated approach are encouraged to gather evidence related to the distribution of Eimeria species that infect large and small domestic ruminants. 


\section{Conclusion}

Using the maximum entropy theory, a habitat suitability model was generated to predict the current potential existence of the parasite with a reliable performance of the prediction model algorithm. Among the variables selected for model construction, $\mathrm{BIO} 4$ and $\mathrm{BIO} 7$ influenced the distribution of different species of Eimeria and showed that the habitat suitability of Eimeria increases in areas with moderate warm climate. Our study may support future studies exploring factors that constrain the distribution of Eimeria as well as strategies aimed at reducing the disease prevalence.

\section{Acknowledgements}

The authors are grateful to Mateo Salazar-Islas for kind assistance in animal sampling and dataset integration.

\section{Financial Support}

This work was supported by the DGAPA-UNAM, project PAPIIT IT200816.

\section{Ethical Standards}

The authors assert that all procedures contributing to this work comply with the ethical standards of the national and institutional guides on the care and use of animals. The experimental protocol was authorized and assigned the number IT200816.

\section{Conflicts of Interest}

The authors declare that no conflict of interest existed.

\section{References}

[1] Chaiyos, J., Suwannatrai, K., Thinkhamrop, K., Pratumchart, K., Sereewong, C., Tesana, S., et al. (2018) MaxEnt Modeling of Soil-Transmitted Helminth Infection Distributions in Thailand. Parasitology Research, 117, 3507-3517.

https://www.ncbi.nlm.nih.gov/pubmed/30120589

https://doi.org/10.1007/s00436-018-6048-7

[2] Pickles, R.S., Thornton, D., Feldman, R., Marques, A. and Murray, D.L. (2013) Predicting Shifts in Parasite Distribution with Climate Change: A Multitrophic Level Approach. Global Change Biology, 19, 2645-2654.

http://www.ncbi.nlm.nih.gov/pubmed/23666800

https://doi.org/10.1111/gcb.12255

[3] Keeton, S.T.N. and Navarre, C.B. (2018) Coccidiosis in Large and Small Ruminants. Veterinary Clinics of North America: Food Animal Practice, 34, 201-208.

https://www.ncbi.nlm.nih.gov/pubmed/29249601 https://doi.org/10.1016/j.cvfa.2017.10.009

[4] Carvalho, B.M., Rangel, E.F., Ready, P.D. and Vale, M.M. (2015) Ecological Niche Modelling Predicts Southward Expansion of Lutzomyia (Nyssomyia) Flaviscutellata (Diptera: Psychodidae: Phlebotominae), Vector of Leishmania (Leishmania) Amazonensis in South America, under Climate Change. PLoS ONE, 10, e0143282. 
https://www.ncbi.nlm.nih.gov/pubmed/26619186

[5] Giles, J.R., Peterson, A.T., Busch, J.D., Olafson, P.U., Scoles, G.A., Davey, R.B., et al. (2014) Invasive Potential of Cattle Fever Ticks in the Southern United States. Parasites and Vectors, 7, 189. https://www.ncbi.nlm.nih.gov/pubmed/24742062 https://doi.org/10.1186/1756-3305-7-189

[6] Pérez-Rodríguez, A., de la Hera, I., Fernández-González, S. and Pérez-Tris, J. (2014) Global Warming Will Reshuffle the Areas of High Prevalence and Richness of Three Genera of Avian Blood Parasites. Global Change Biology, 20, 2406-2016. https://www.ncbi.nlm.nih.gov/pubmed/24488566 https://doi.org/10.1111/gcb.12542

[7] Valencia-López, N., Malone, J.B., Carmona, C.G. and Velásquez, L.E. (2012) Climate-Based Risk Models for Fasciola Hepatica in Colombia. Geospatial Health, 6, S67-S85. http://www.ncbi.nlm.nih.gov/pubmed/23032286 https://doi.org/10.4081/gh.2012.125

[8] Charlier, J., Bennema, S.C., Caron, Y., Counotte, M., Ducheyne, E., Hendrickx, G., et al. (2011) Towards Assessing Fine-Scale Indicators for the Spatial Transmission Risk of Fasciola Hepatica in Cattle. Geospatial Health, 5, 239-245.

http://www.ncbi.nlm.nih.gov/pubmed/21590674

https://doi.org/10.4081/gh.2011.176

[9] York, E.M., Butler, C.J. and Lord, W.D. (2014) Global Decline in Suitable Habitat for Angiostrongylus (=Parastrongylus) cantonensis: The Role of Climate Change. PLoS ONE, 9, e103831. https://www.ncbi.nlm.nih.gov/pubmed/25122457 https://doi.org/10.1371/journal.pone.0103831

[10] Suwannatrai, A., Pratumchart, K., Suwannatrai, K., Thinkhamrop, K., Chaiyos, J., Kim, C.S., et al. (2017) Modeling Impacts of Climate Change on the Potential Distribution of the Carcinogenic Liver Fluke, Opisthorchis viverrini, in Thailand. Parasitology Research, 116, 243-250. https://www.ncbi.nlm.nih.gov/pubmed/27774575 https://doi.org/10.1007/s00436-016-5285-x

[11] Rubel, F., Brugger, K., Monazahian, M., Habedank, B., Dautel, H., Leverenz, S., et al. (2014) The First German Map of Georeferenced Ixodid Tick Locations. Parasites and Vectors, 7, 477. http://www.ncbi.nlm.nih.gov/pubmed/25301245 https://doi.org/10.1186/s13071-014-0477-7

[12] Walter, M., Brugger, K. and Rubel, F. (2016) The Ecological Niche of Dermacentor marginatus in Germany. Parasitology Research, 115, 2165-2174.

https://www.ncbi.nlm.nih.gov/pubmed/26993325 https://doi.org/10.1007/s00436-016-4958-9

[13] Alcala-Canto, Y., Figueroa-Castillo, J.A., Ibarra-Velarde, F., Vera-Montenegro, Y., Cervantes-Valencia, M.E., Salem, A.Z.M., et al. (2018) Development of the First Georeferenced Map of Rhipicephalus (Boophilus) spp. in Mexico from 1970 to Date and Prediction of Its Spatial Distribution. Geospatial Health, 13, 624. https://www.ncbi.nlm.nih.gov/pubmed/29772883

[14] García, E. (1981) Modificaciones al Sistema de Clasificación Climática de Köppen Para Adaptarlo a las Condiciones de la República Mexicana. México, D.F., México.

[15] García E: Climas (Clasificación de Köppen, Modificado por García) (1998) Escala 1:1000000. Comisión Nacional Para el Conocimiento y uso de la Biodiversidad (CONABIO), Mexico.

[16] Musella, V., Catelan, D., Rinaldi, L., Lagazio, C., Cringoli, G. and Biggeri, A. (2011) Covariate Selection in Multivariate Spatial Analysis of Ovine Parasitic Infection. Preventive Veterinary Medicine, 99, 69-77. 
http://www.ncbi.nlm.nih.gov/pubmed/21167615 https://doi.org/10.1016/j.prevetmed.2010.11.012

[17] Tanner, E.P., Papeş, M., Elmore, R.D., Fuhlendorf, S.D. and Davis, C.A. (2017) Incorporating Abundance Information and Guiding Variable Selection for Climate-Based Ensemble Forecasting of Species' Distributional Shifts. PLoS ONE, 12, e0184316. https://www.ncbi.nlm.nih.gov/pubmed/28886075

[18] Hijmans, R., Cameron, S., Parra, J., Jones, P. and Jarvis, A. (2005) Very High Resolution Interpolated Climate Surfaces for Global Land Areas. International Journal of Climatology, 25, 1965-1978. https://doi.org/10.1002/joc.1276

[19] Phillips, S.J. and Dudík, M. (2006) Schapire RE: Maxent Software for Modeling Species Niches and Distributions (Version 3.4.1). http://biodiversityinformatics.amnh.org/open_source/maxent/

[20] Zhang, K., Yao, L., Meng, J. and Tao, J. (2018) Maxent Modeling for Predicting the Potential Geographical Distribution of Two Peony Species under Climate Change. Science of the Total Environment, 634, 1326-1334.

https://www.ncbi.nlm.nih.gov/pubmed/29710632 https://doi.org/10.1016/j.scitotenv.2018.04.112

[21] McQuillan, M.A. and Rice, A.M. (2015) Differential Effects of Climate and Species Interactions on Range Limits at a Hybrid Zone: Potential Direct and Indirect Impacts of Climate Change. Ecology and Evolution, 5, 5120-5137.

https://www.ncbi.nlm.nih.gov/pubmed/26640687 https://doi.org/10.1002/ece3.1774

[22] Qin, H., Gao, X., Wang, H. and Xiao, J. (2016) Relative Importance of Meteorological and Geographical Factors in the Distribution of Fasciola hepatica Infestation in Farmed Sheep in Qinghai Province, China. Parasite, 23, Article No. 59.

https://www.ncbi.nlm.nih.gov/pubmed/28000591 https://doi.org/10.1051/parasite/2016070

[23] Fand, B.B., Kumar, M. and Kamble, A.L. (2014) Predicting the Potential Geographic Distribution of Cotton Mealybug Phenacoccus Solenopsis in India Based on MAXENT Ecological Niche Model. Journal of Environmental Biology, 35, 973-982. https://www.ncbi.nlm.nih.gov/pubmed/25204075

[24] Efron, B. (1982) The Jackknife, the Bootstrap, and Other Resampling Plans. Philadelphia. Society for Industrial and Applied Mathematics, Philadelphia, PA. https://doi.org/10.1137/1.9781611970319

[25] Phillips, S.J., Dudík, M., Elith, J., Graham, C.H., Lehmann, A., Leathwick, J., et al. (2009) Sample Selection Bias and Presence-Only Distribution Models: Implications for Background and Pseudo-Absence Data. Ecological Applications, 19, 181-197. http://www.ncbi.nlm.nih.gov/pubmed/19323182 https://doi.org/10.1890/07-2153.1

[26] Phillips, S., Anderson, R. and Schapire, R. (2006) Maximum Entropy Modeling of Species Geographic Distribution. Ecological Modelling, 190, 231-259. https://doi.org/10.1016/j.ecolmodel.2005.03.026

[27] Graham, M.H. (2003) Confronting Multicollinearity in Ecological Multiple Regression. Ecology, 84, 2809-2815. https://doi.org/10.1890/02-3114

[28] Wolter, K.M. (2007) The Jackknife Method. In: Wolter, K.M., Ed., Introduction to Variance Estimation, Springer, New York, 151-193. https://doi.org/10.1007/978-0-387-35099-8_4

[29] INEGI (2017) Guía para la interpretación de cartografía climática. Edited by Geografía INdEy. INEGI, México. 
[30] Mai, K., Sharman, P.A., Walker, R.A., Katrib, M., De Souza, D., McConville, M.J., et al. (2009) Oocyst Wall Formation and Composition in Coccidian Parasites. Memórias do Instituto Oswaldo Cruz, 104, 281-289.

https://www.ncbi.nlm.nih.gov/pubmed/19430654 https://doi.org/10.1590/S0074-02762009000200022

[31] Belli, S.I., Smith, N.C. and Ferguson, D.J. (2006) The Coccidian Oocyst: A Tough Nut to Crack! Trends in Parasitology, 22, 416-423.

https://www.ncbi.nlm.nih.gov/pubmed/16859995 https://doi.org/10.1016/j.pt.2006.07.004

[32] Das, M., Deka, D.K., Sarmah, P.C., Islam, S. and Sarma, S. (2015) Diversity of Eimeria Spp. in Dairy Cattle of Guwahati, Assam, India. Veterinary World, 8, 941-945. http://www.ncbi.nlm.nih.gov/pubmed/27047181 https://doi.org/10.14202/vetworld.2015.941-945

[33] Nahed-Toral, J., López-Tirado, Q., Mendoza-Martínez, G., Aluja-Schunemann, A. and Trigo-Tavera, F.J. (2003) Epidemiology of Parasitosis in the Tzotzil Sheep Production System. Small Ruminant Research, 49, 199-206.

http://dx.doi.org/10.1016/S0921-4488(03)00076-2 https://doi.org/10.1016/S0921-4488(03)00076-2

[34] Rodríguez-Vivas, R., Gris, L., Pérez de León, A., Silva, V., Torres-Acosta, J., Fragoso-Sánchez, H., et al. (2017) Potential Economic Impact Assessment for Cattle Parasites in Mexico. Review. Revista Mexicana de Ciencias Pecuarias, 8, 61-74. https://doi.org/10.22319/rmcp.v8i1.4305

[35] Lassen, B., Viltrop, A. and Järvis, T. (2009) Herd Factors Influencing Oocyst Production of Eimeria and Cryptosporidium in Estonian Dairy Cattle. Parasitology Research, 105, 1211-1222. https://www.ncbi.nlm.nih.gov/pubmed/19557434 https://doi.org/10.1007/s00436-009-1540-8

[36] Sun, P., Wronski, T., Bariyanga, J.D. and Apio, A. (2018) Gastro-Intestinal Parasite Infections of Ankole Cattle in an Unhealthy Landscape: An Assessment of Ecological Predictors. Veterinary Parasitology, 252, 107-116. https://www.ncbi.nlm.nih.gov/pubmed/29559130 https://doi.org/10.1016/j.vetpar.2018.01.023

[37] Acheson, E.S., Plowright, A.A. and Kerr, J.T. (2015) Where Have All the Mosquito Nets Gone? Spatial Modelling Reveals Mosquito Net Distributions Across Tanzania Do Not Target Optimal Anopheles Mosquito Habitats. Malaria Journal, 14, 322. http://www.ncbi.nlm.nih.gov/pubmed/26283538 https://doi.org/10.1186/s12936-015-0841-x 